\title{
AN ANALYSIS METHODOLOGY OF THE EFFECT OF USING DIFFERENT TRACKING TIME-STEPS ON THE NET ENERGY GAIN OF A CSP POWER PLANT
}

\author{
Ahmed M. Elsayed ${ }^{1}$, A. Elsamahy ${ }^{2}$, M. Rady ${ }^{3}$ and Amr M. A. Amin ${ }^{4}$ \\ ${ }^{1}$ Mechanical Engineering Department, , (Mechatronics Branch) The Higher Technological Institute, \\ Sharqiya,Egypt \\ ${ }^{2}$ Electrical power \& Machine Department, Helwan University, Cairo, Egypt \\ ${ }^{3}$ Mechanical Engineering Department, Helwan University, Cairo, Egypt \\ ${ }^{4}$ Academy of Scientific Research and Technology, Cairo, Egypt
}

\begin{abstract}
in central receiver solar power plant, heliostat tracking accuracy affects the optical efficiency and the amount of energy received at the target. In the present article, an integrated analysis of the effect of using different solar tracking time-steps on the energy consumption and gain of a central receiver system is developed. The drive system energy consumption is calculated by using a Solidworks model of the heliostat mechanical drive system. This Solidworks model is interfaced to a Labview model containing the model of the electrical drive and control systems. The solar energy collected at the receiver is calculated using Monte Carlo ray tracing software.
\end{abstract}

Keywords: Heliostat solar system, Electric Drives, Labview, solidworks, Energy.

\section{INTRODUCTION}

With continuous increase in global warming and pollution level and the increase in petroleum fuel cost, there is an orientation towards utilizing renewable resources around the world. Solar energy is considered one of the most utilized renewable energy sources. Among the several technologies in solar energy is the concentrated solar power (CSP) plant, which can be classified to four different types; i.e. Parabolic Trough, Parabolic Dish, Linear Fresnel and Central Tower Receiver (CTR). In the recent years, there is a focus in development and commercial of the CTR because of its high efficiency and low cost [1].

The CTR consists of a circular array of heliostats. These heliostats can be arranged in specified pattern to reflect the incident sun rays on the target. The target is mounted at the top of a central tower in the plant [2]. This process is used to convert the concentrated thermal energy to other usage like feeding thermal loads or generating electricity. Each heliostat in the field requires different angles of tracking according its position from the receiver. The sun tracking by the heliostats is the first stage in CTR operation, and its precision affects the solar energy received at the target. Hence, the power output of CTR increases with the use of effective and efficient solar tracking techniques.

According to astronomical data and solar position algorithm, the rate of change of the sun position is not linear during the day and seasons, in addition it differs from location to another. To maximize the solar energy reflected by the heliostat on the central receiver, the heliostat tracker should follow the rate of change in sun position with specified tracking time-step. On the other hand, there is energy consumed by the drive system for tracking the sun in both azimuth and elevation angles. 
In open loop control system for heliostat tracking and control, there is no feedback measurement of radiation received at the target to correct the heliostat position [3]. In closed loop control systems [3, 4], a dynamic measurement of radiation at receiver to compute the spillage is used as a feedback to reduce heliostat tracking error. Most of heliostats tracking motions are discrete. However, the sun motion is continuous. A continuous tracking of heliostat is presented in [4]. The system is based on using a continuous motion in heliostat tracking which is based on an electronic speed control unit to control the speed of two AC motors. This aims to adjust the heliostat position with an error range of 1$1.53 \mathrm{mrad}$. This technique reduces the tracking error to negligible level. An artificial vision based control is proposed, for automatic positioning of heliostat offset correction [5]. A charge coupled device (CCD) camera is used to correct the heliostat deviation occurred by taking the distance between the target and the sunbeam projection from the heliostat

Heliostat tracking accuracy affect the optical efficiency of CTR and the amount of energy collected at the target. A recent analysis has been performed to investigate the optical efficiencies of the first Korean CTR using a Monte-Carlo ray tracing code. The optical efficiency has been broken into six components. The results obtained in winter, summer, and autumn indicate that the optical efficiency is best in autumn but worse in summer as mentioned in [6].

In the previous studies, the emphasis was focused on minimizing the tracking error of heliostats from the point of view of control system. In practice, the most popular linear two-axis local driving system of heliostat consists of two linear driving actuators, the driving mechanism with rotary joints, and the controller. Optimization of tracking time step should consider both the energy gain at the receiver and the energy consumption of the drive mechanism which is dependent on both the mechanical structure of the heliostat and its drive system components. Therefore, in order to reach the optimal tracking of heliostats, an integrated analysis that concurrently considers the interactions between the mechanical and control subsystems is necessary. This analysis should consider three aspects that my affect the decision on the optimum time-step. The first aspect includes the mechanical structure of the heliostat, facet, mirror and all the required fixtures. The second one includes the drive system which is composed of two DC linear actuators for elevation and azimuth angles taking into consideration the model of power screw and DC motor parameters. The third aspect is the optical analysis concerning the solar radiation received on the target and the spillage occurred as a result of using different tracking time-steps.

In the present article, an integrated analysis of the effect of using different solar tracking time-steps on the energy consumption and gain of a central receiver system is developed. The drive system energy consumption is calculated by using a Solidworks model of the heliostat mechanical drive system. This Solidworks model is interfaced to a Labview model containing the model of the electrical drive and control systems. The solar energy collected at the receiver is calculated using Monte Carlo ray tracing software. Results of energy analysis using the proposed methodology are presented and discussed.

\section{HELIOSTAT MECHANICAL MODEL}

To represent all the physical dynamics in the mechanical structure and drive system power screw, a 3D CAD model is developed for the heliostat and for the linear actuator using Solidworks software. The CAD model used takes into account the heliostat, facet, pedestal, linear actuators and other fixtures as shown in Fig. 1. The criterion taken in consideration during mechanical design is to develop a low-cost heliostat using azimuth-elevation tracking method with accuracy of $1 \mathrm{mrad}$. The heliostat facet is $3 \mathrm{~m} 2$ using a linear actuator for both the azimuth and elevation angels. 


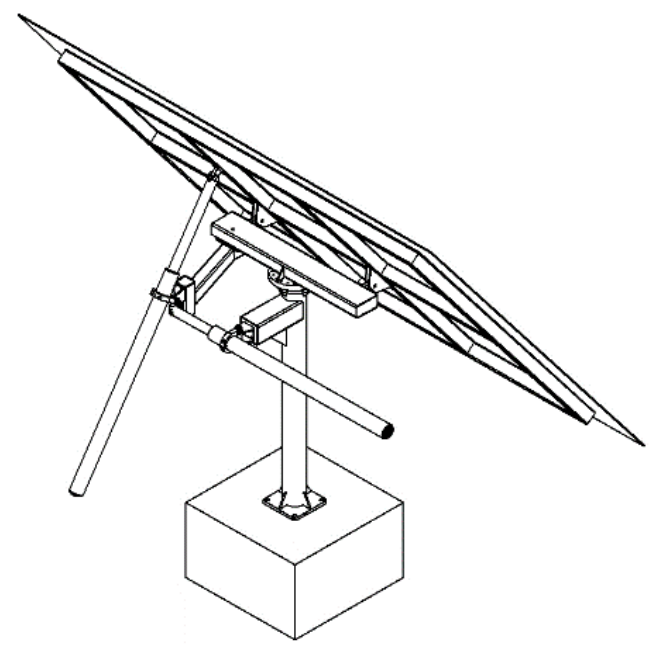

Fig. 1 Heliostat 3D CAD Model

The selection of linear actuator is based on two conditions. The first is the maximum exerted torque of the mechanical structure on the actuator. This maximum value has been determined in the current work from the mechanical modelling of the proposed system in the elevation angle motion using Solidworks motion analysis. The result from Solidworks motion analysis is $146 \mathrm{~m}$ N.m. as show in Fig. 2. In this design, it is assumed that in the azimuth angle motion, the torque is nearly constant and equals 0.9 m N.m.

The second condition is the stroke length of the actuator to move the heliostat by $0-90^{\circ}$ degrees in elevation angle and $120^{\circ}$ degrees in azimuth angle. The geometry of motion is extracted from the mechanical model, from which a relation between the linear and angular motions in both azimuth and elevation angles is computed as shown in Fig 3. Equation 1 and 2 computed from the analysis of the mechanical model geometry as shown in Fig 3 using trigonometric calculations. Equation 1 is the relation between the heliostat elevation angle the linear motion distance moved by the linear actuator, while equation 2 is the relation between the heliostat azimuth angle and the linear motion of linear actuator. In addition, this relation is used to control the DC motor motions.

$$
\begin{aligned}
& \theta=\cos ^{-1}\left(\frac{L^{2}-306492.8401}{-301537.544}\right)-13.42331 \\
& \theta=\cos ^{-1}\left(\frac{L^{2}-223112.84}{-205640.1284}\right)-3.90926285
\end{aligned}
$$

Heliostat Elevation Load Torque

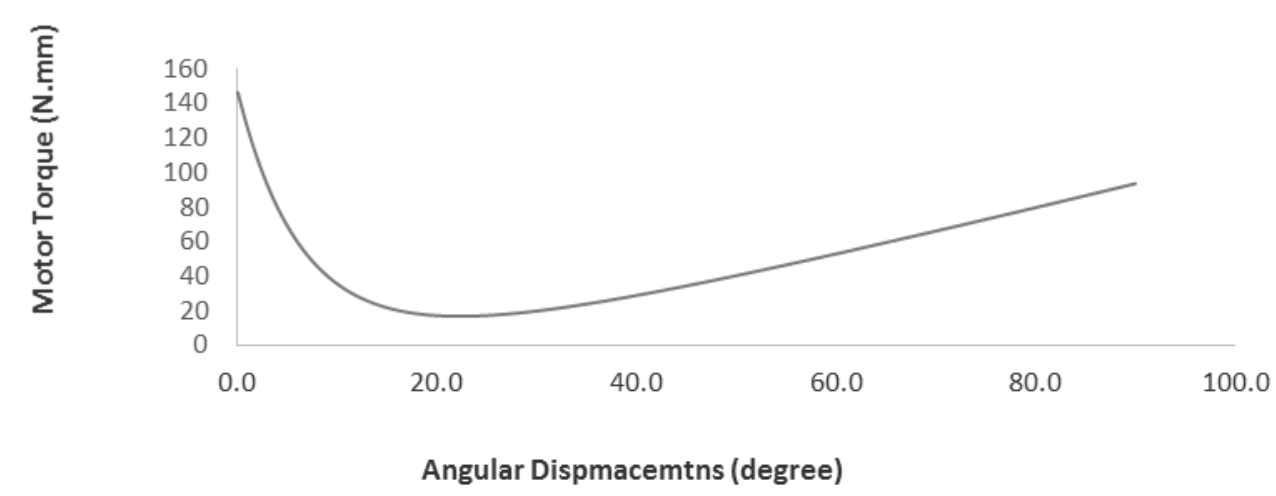

Fig. 2 Elevation motion load torque computed form Solidworks motion analysis 


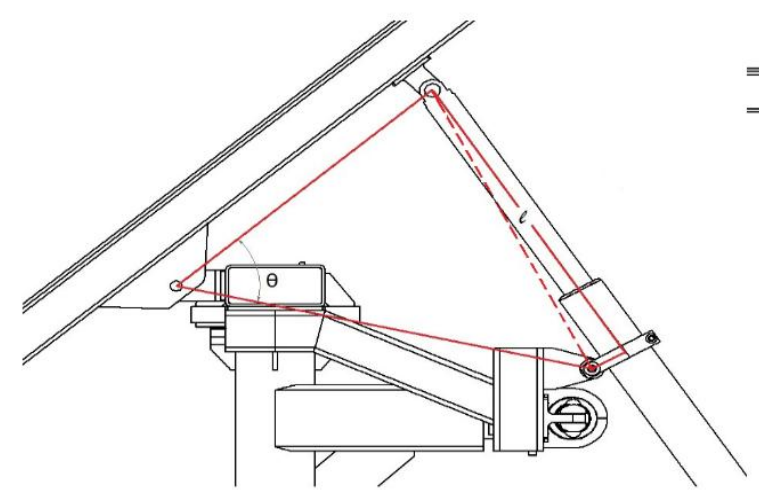

(a)

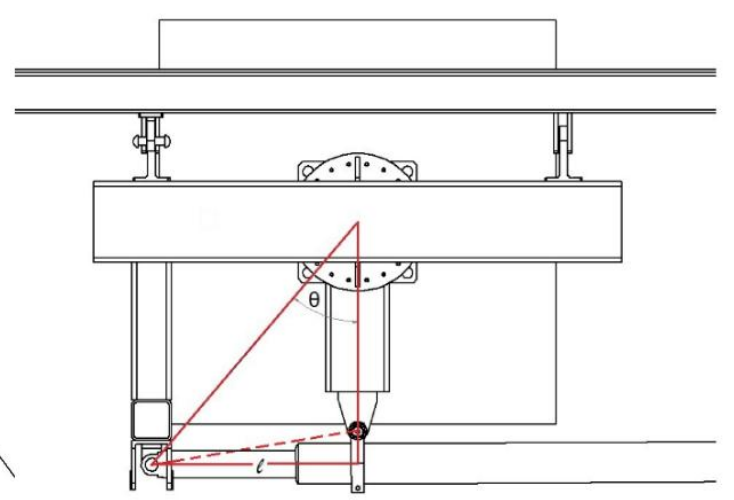

(b)

Fig. 3 (a) Heliostat Elevation motion geometry

(b) Heliostat azimuth motion geometry

For the energy consumption calculation, it is essential to compute the load torque exerted on the DC motor. Therefore, Solidworks motion study is used where the load torque resulted from the mechanical structure in both elevation and azimuth angle is computed. This torque is calculated taking into consideration the dynamics of power screw, mechanical structure, gravity and friction between moving parts. The load torque component in elevation angle motion is nonlinear. However, the load torque in azimuth angle motion is nearly constant.

\section{CONTROL AND DRIVE SYSTEM MODELLING}

The first stage in control is to calculate the sun position, which is defined by the sun azimuth and elevation angles. There have been several methods used in sun tracking systems for this calculation. The method used in the presented work is Solar Position Algorithm (SPA). This algorithm is used to calculate sun position within years -2000 to 6000 with uncertainties \pm 0.00030 . SPA is described in "Astronomical Algorithm" by Meeus J [7] and stated in steps by NREL in [8].To compute the energy consumption by the drive system for moving the heliostat, integration is done between the mechanical model and drive system control model in order to include all the dynamics of mechanical and drive system. The software used to simulate the mechanical model is Solidworks, while the drive system is Labview.

The inputs to the system are the local time, time zone and location longitude and latitude. The SPA block uses these inputs to calculate the sun azimuth $(\Psi)$ and elevation $(\alpha)$ angle using solar position algorithm. In addition, it calculates the azimuth $(\Psi \mathrm{H})$ and elevation $(\alpha \mathrm{H})$ angles of the heliostats in order to reflect the sun beam on the target. The heliostat elevation and azimuth angles are deduced from three vectors, $\mathrm{S}$ which the unit vector from heliostat centre to the sun, $\mathrm{H}$ is the normal unit vector from heliostat surface and $\mathrm{R}$ which is the unit vector directed from heliostat to the receiver [9]. To reflect the sun beam on receiver the angle between $\mathrm{R}$ and $\mathrm{S}$ vector should equal to the angle between $\mathrm{H}$ and $\mathrm{S}$ vector as illustrated in Fig 4. Hence, the values of unit vectors depend on the position of the heliostat in the filed with respect to the receiver.

The SPA block, which is the Labview, calculates the heliostat angles and transfers it to the mechanical model block, which is the Solidworks. At this stage, the heliostat mechanical model moves to the targets angles and the Solidworks program computes the torque exerted by the mechanical structure on the actuator. Furthermore, the Solidworks transfers the computed torque to the drive system model within Labview to compute the energy consumption by both the azimuth and elevation actuators during the heliostat motion to the target position. A block diagram for the simulation model is shown in Fig 5. 


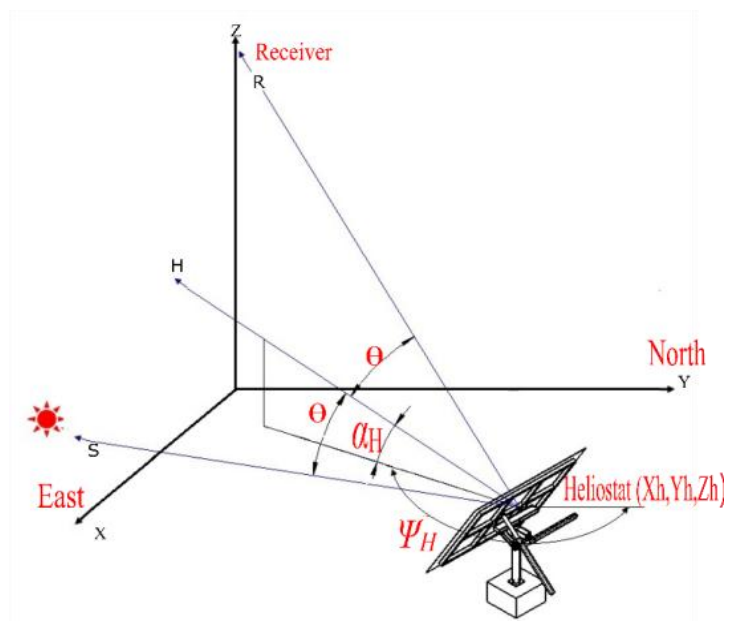

Fig. 4 control simulation schematics

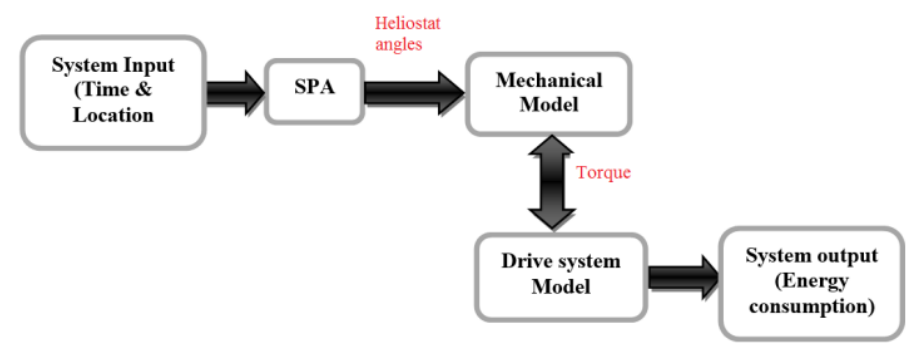

Fig. 5 tracking system block diagram

To study the effect of the solar tracking time step on energy consumption, the simulations have been done using different values of fixed solar tracking time-step from sunrise to sunset for a representative day in winter chosen to be 20th of January. The results show that the use of a small time-step tracking consumes more energy compared to large step. This is because of the starting current of the motor, for $15 \mathrm{sec}$ step the heliostat will move a $1^{\circ}$ degree in more discrete steps than $30 \mathrm{sec}$ and $60 \mathrm{sec} \mathrm{step}$, and since the motor consume more current during starting this will cause the energy consumption in small time step consume more energy than big time step. The energy consumed by the actuators while using three different time-step values i.e. 15, 30 and 60 seconds are shown in Fig 6.

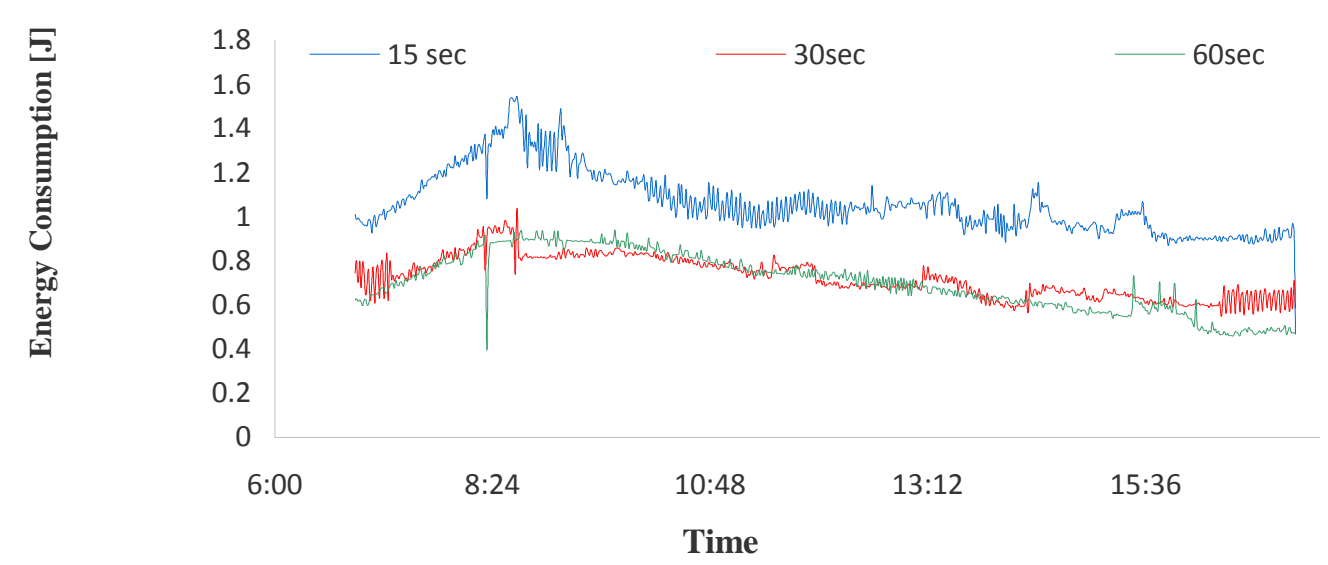

Fig. 6 Actuator energy consumption using different tracking step 


\section{SOLAR RADIATION MODEL}

After studying the effect of the different time-step on the energy consumed by the drive system, it is important to study the same effect on the energy gained from the solar system. This section presents the energy gained from the heliostat reflecting the solar radiation on the target. In the presented work, the mathematical model used to predict the solar radiation under clear sky condition is HayDavies model. This model is used to calculate the direct, diffuse and reflected radiations. This model can be described by the relations given in Eq. (3) and the parameters are defined in the nomenclature at the beginning of the article. More details about this model can be found in [10].

$$
\begin{gathered}
\mathrm{I}_{\mathrm{d}}=\mathrm{I}_{\mathrm{o}}(\cos \varphi)\left(\mathrm{T}_{\mathrm{o}} \mathrm{T}_{\mathrm{R}}-\mathrm{a}_{\mathrm{w}}\right) \mathrm{T}_{\mathrm{A}} \\
I_{a s}=I_{o}(\cos \varphi)\left[T_{o}\left(1-T_{R}\right) T_{A}(0.5)+\left(T_{o} T_{R}-a_{w}\right)\left(1-T_{A}\right) W_{o} B_{a}\right] \\
I_{G}=r_{g} r_{s}\left(I_{d}+I_{a s}\right) /\left(1-r_{g} r_{s}\right) \\
I_{T}=I_{d}+I_{a s}+I_{G}
\end{gathered}
$$

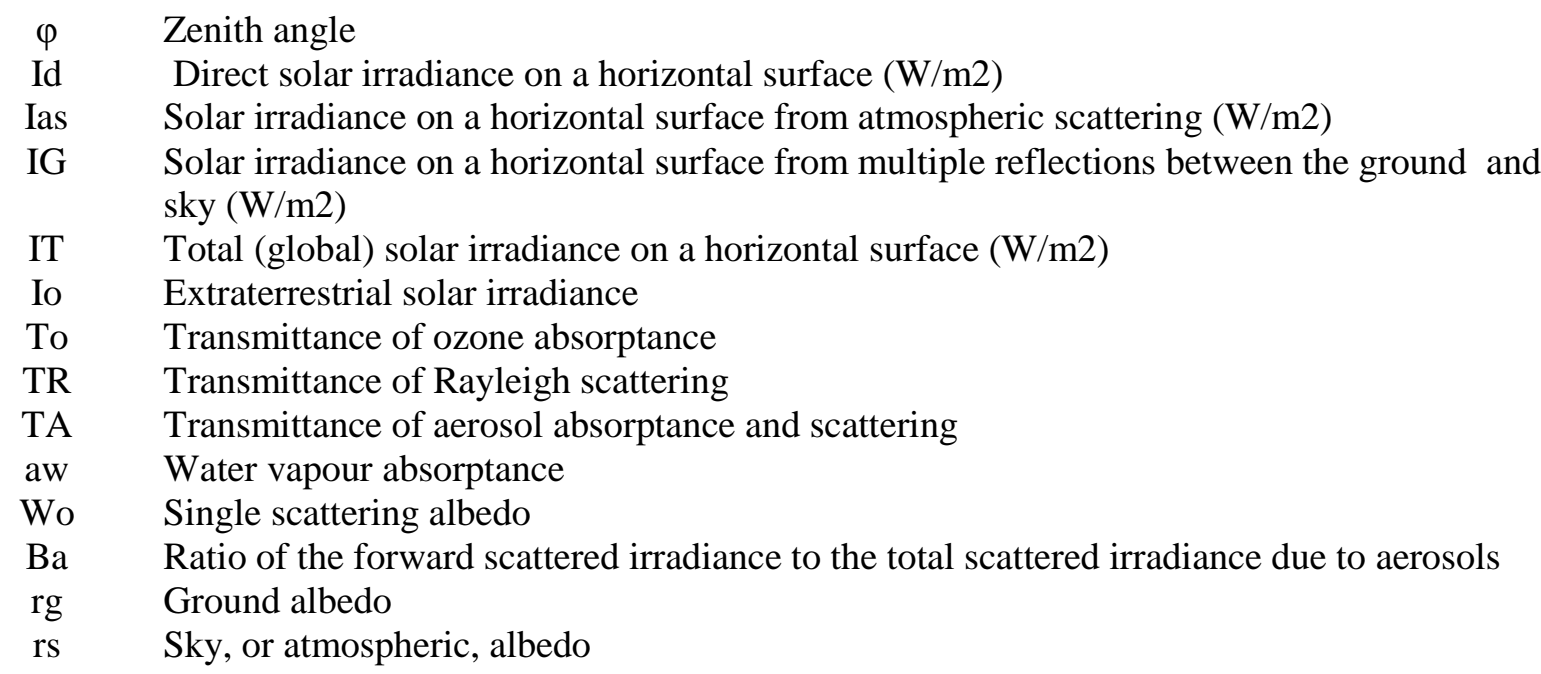

Fig. 7, shows the calculated total solar irradiance on a horizontal surface for location $29.8680^{\circ} \mathrm{N}$ and $31.3156^{\circ} \mathrm{E}$, (Helwan region in Egypt) in July. It can be observed that the maximum horizontal irradiance in the area is $1100 \mathrm{w} / \mathrm{m}^{2}$. To ensure the accuracy of the solar radiation model, a real measured data for solar radiation taken from a weather station installed at Cairo Airport as shown in Fig 8 , the measured data is similar to the solar radiation but with a small different. It shown also the maximum irradiance $1077 \mathrm{w} / \mathrm{m}^{2}$.

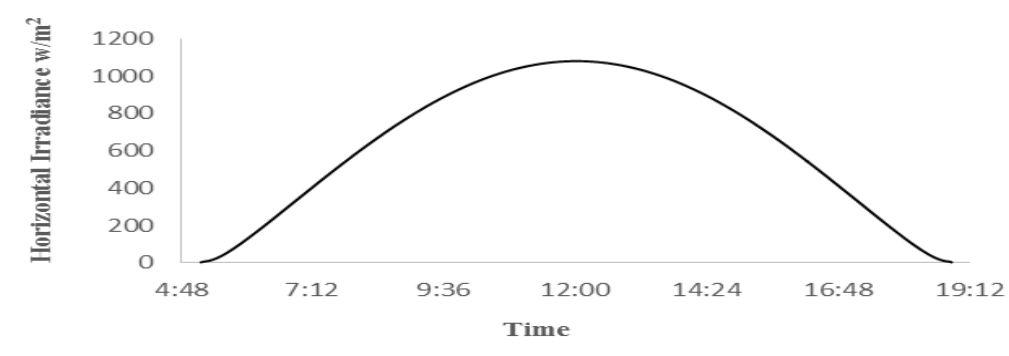

Fig. 7 solar radiation in Helwan Egypt computed from Day Havis solar radiation model 


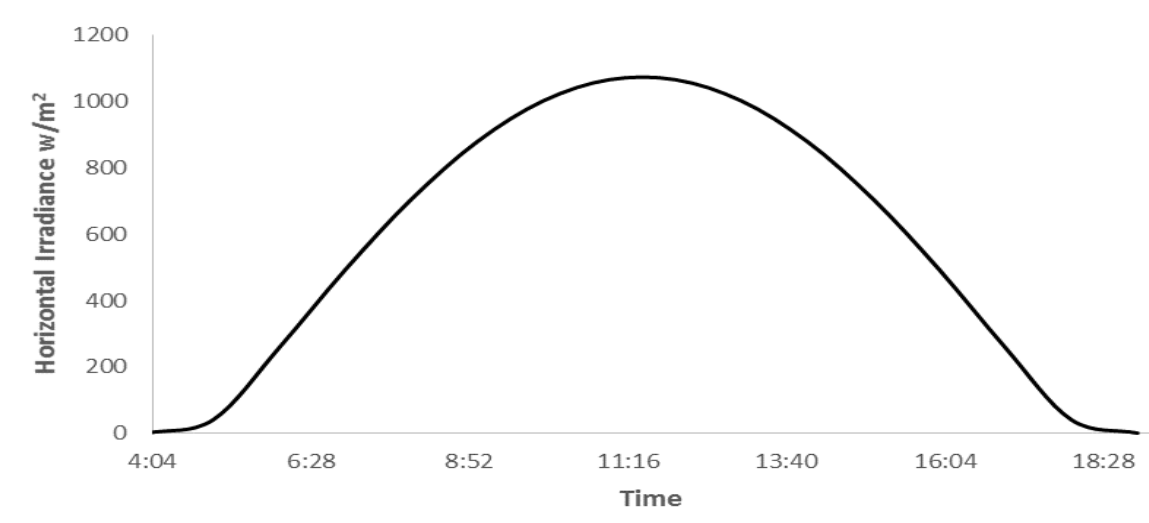

Fig.8 Solar radiation measured from weather station installed at Cairo airport .

\section{OPTICAL AND RECEIVED ENERGY ANALYSIS}

The effect of solar tracking time-step from optical and energy received perspective will be discussed in this section. The software used is Tonatiuh, which is an open source object-oriented Monte Carlo ray tracing program [11]. The analysis has been performed on one heliostat in the field.

The important factor is to maximize the energy received at the central tower by minimizing the solar radiation losses caused by spillage. Therefore, an optical analysis is done for one heliostat in the field, to study the effect of different solar tracking time-step on the rate of spillage occurrence at the receiver and therefore the power received from the heliostat. The simulation is performed for different tracking time-step values i.e. 30, 60 and $120 \mathrm{sec}$ in order to know the effect of energy received with respect to the sun tracking time-step. Regarding the landscape parameters used in Tonatiuh model, the heliostat width and height dimensions are $1.8 \mathrm{~m}$ and $1.6 \mathrm{~m}$, respectively. It is located at $100 \mathrm{~m}$ east and $50 \mathrm{~m}$ north from the central tower. The receiver is an internal type with hexagon shape and it is height from the ground is $43 \mathrm{~m}$.

Fig. 9 shows the power received at the target for continuous tracking when adjusting the heliostat position with the change in sun position in a continuous manner. Furthermore, it shows also the power received at the target as a using different discrete tracking time steps. The difference between the power values between discrete and continuous tracking is due to spillage caused by not moving the heliostat to the correct position at different values of tracking time step. As shown the power received at the target when there is spillage is decreasing as the tracking time step increase. Fig. 10 shows the power losses as a result of not positioning the heliostat to the correct position at different values of tracking time step. It can be observed that the power losses increase with the increase in tracking time step. The difference between the power losses of each tracking time step decrease during the end of the day.

The present results show the usefulness of the present methodology in performing an energy analysis of heliostat drive system. For the present configuration, the energy loss due to spillage using high values of tracking time step is significant as compared to the energy consumption of the drive system. Further analysis shall be carried out for different locations of heliostats in the field and for different seasons. 


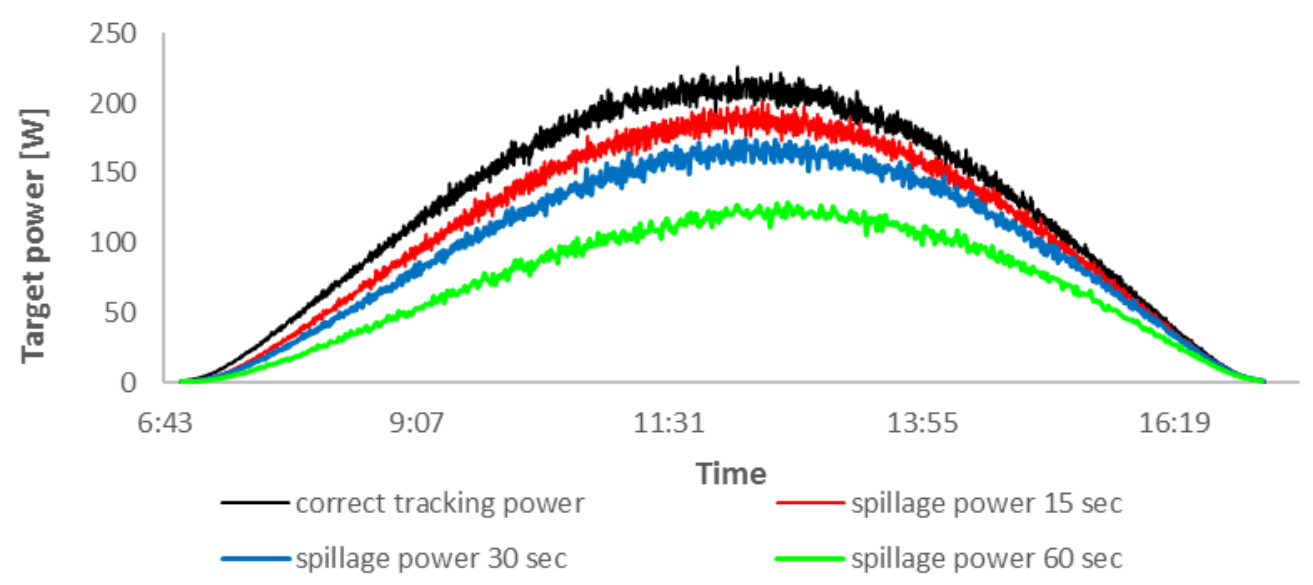

Fig. 9: Power received at the target during using continuous tracking and discrete tracking with different values of tracking time step.

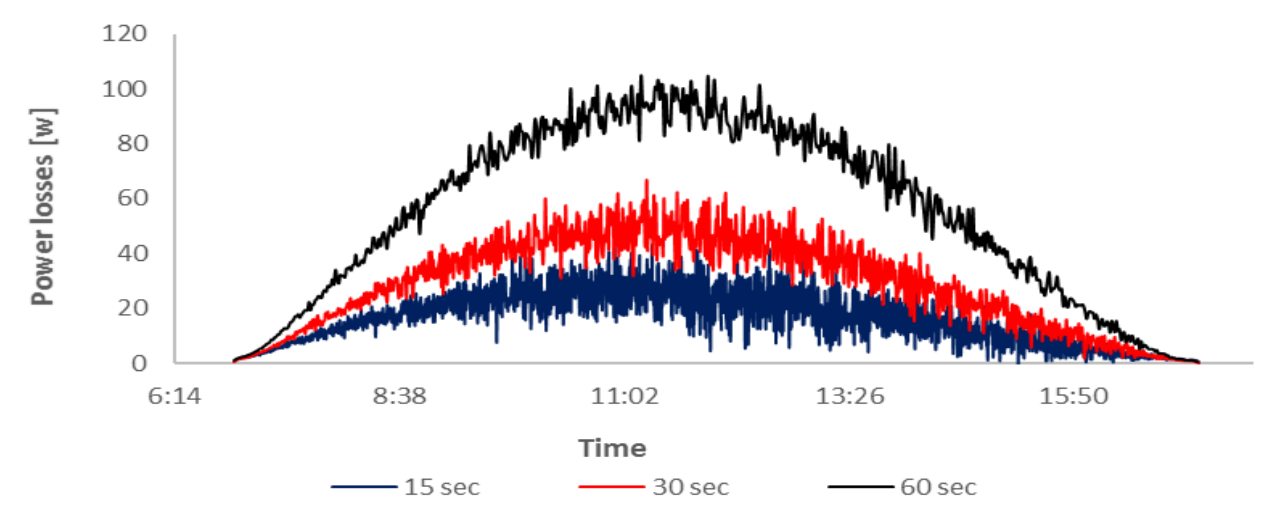

Fig 10. Power losses due to spillage at different values of tracking time step.

\section{CONCLUSIONS}

This article present an integrated approach to analyze the power received at the central receiver and the energy consumption of drive system as a function of heliostat tracking time step. The drive system energy consumption is calculated by using a Solidworks model of the heliostat mechanical drive system. This Solidworks model is interfaced to a Labview model containing the model of the electrical drive and control systems. The solar energy collected at the receiver is calculated using Monte Carlo ray tracing software. The results show that the spillage losses decrease with the decrease of tracking time step. These losses are relatively high at the solar noon and decrease by the end of the day. On the other hand, the drive system energy consumption increases with the decrease of tracking time step. Further analysis for different heliostats structure, locations, and seasons is planned in the future.

\section{ACKNOWLEDGEMENTS}

This work was funded and supported by a grant from the Academy of Scientific Research and Technology. (ASRT) and from the European Union's Seventh Framework Program (FP7/2007-2013) through MATs project under grant agreement no. 268219. The authors are grateful to the ASRT and European Union's Seventh Framework Program and also to the staff of the Energy Technologies Department (DTE) unit of ENEA-Casaccia research center (Rome, Italy) for providing the required data regarding the heliostat mechanical model design. 


\section{REFERENCES}

[1] G. J. Kolb, S. A. Jones and M. W. Donnelly, "Heliostat Cost Reduction Study", sandia National Laboratories, California, SAND2007-3293, JUNE 2007.

[2] K. Lovegrove and W. Stein, " central tower concentrating solar power (CSP) systems" in Concentrating solar power technology principles, developments and applications, vol 21, Sawston, Cambridge, Woodhead publishing limited, 2012, ch 8, pp. 240 - 243.

[3] A.Kribus, I. Vishnevetsky, A. yogev and T. Rubinov, "Closed loop control of heliostats", Elsevier, vol 29, pp. 905-913, April 2004.

[4] A.Kribus, I. Vishnevetsky, A. yogev and T. Rubinov, "Continuous Tracking of Heliostats", Solar Energy Engineering, vol 126, Aug 2004.

[5] M. Berenguel, F.R. Rubio, A. Valverde, P.J. Lara and M.R. Arahal, “ An artificial vision-based control system for automatic heliostat positioning offset correction in a central receiver solar power plant", Elsevier, vol 76, pp. 563 - 575, 2004.

[6] J. Lee, K. Kim, N. Lee, k. Yoon, H. Kang and H.park, "calculation of optical efficiency for the first central receiver solar concentrator system in korea", Elsevier, vol 69, pp. 126 - 131, 2015.

[7] Jean Meeus “Astronomical Algorithms", 2nd ed, Richmond, Birginia, Willmann-Bell, Inc.

[8] I. Reda and A. Andreas, "Solar position algorithm for solar radiation applications", Elsevier, solar Energy, vol 76, PP. 577 - 589, 2004.

[9] D. I. Lee, W. J. Jeon, S. W. Baek, "Optimal design and control of heliostat for solar power generation", LACSIT International journal of engineering and technology, vol 4, No. 4, Aug 2012.

[10] R.E. Bird and R. L. Hulstrom, "A simplified clear sky model for direct and diffuse insolation on horizontal surfaces”, Solar Energy Research Institute, Colorado, SERI/TR-642-761, ppt. 4, Feb 1981.

[11] Manuel J. Blanco, "Tonatiuh: An object oriented, distributed computing, Monte-carlo ray tracer for the design and simulation of solar concentrating systems", Major Fy 2006/2007 